Mots. Les langages du politique

$96 \mid 2011$

Les discours politiques. Approches interactionnistes et multimodales

\title{
Actualité bibliographique
}

Les langages du politique

Josette Lefèvre

\section{OpenEdition \\ Journals}

Édition électronique

URL : https://journals.openedition.org/mots/20334

DOI : $10.4000 /$ mots.20334

ISSN : 1960-6001

Éditeur

ENS Éditions

Édition imprimée

Date de publication : 5 septembre 2011

ISBN : 978-2-84788-316-9

ISSN : 0243-6450

Référence électronique

Josette Lefèvre, «Actualité bibliographique », Mots. Les langages du politique [En ligne], 96 | 2011, mis en ligne le 05 septembre 2013, consulté le 23 avril 2022. URL : http://journals.openedition.org/mots/ 20334 ; DOI : https://doi.org/10.4000/mots.20334 


\section{Actualité bibliographique Les langages du politique}

Agostino Marc, CAdilhon François, MoISSET Jean-Pierre, SuIRE Éric éd., 2011, Les religions et l'information. XVI $I_{-x x l^{e}}$ siècles, Bordeaux, Presses universitaires de Bordeaux, $390 \mathrm{p}$.

Albert Luce, Nicolas Loïc éd., 2010, Polémique et rhétorique. De l'Antiquité à nos jours, Bruxelles, De Boeck, $464 \mathrm{p}$.

Amossy Ruth, 2010 [2000], L'argumentation dans le discours, $3^{\mathrm{e}}$ édition actualisée et augmentée, Paris, Armand Colin, $256 \mathrm{p}$.

AnCElet-NetTER Dominique, 2010, La dette, la dîme, le denier. Une analyse sémantique du vocabulaire économique et financier au Moyen Âge, Villeneuve d'Ascq, Presses universitaires du Septentrion, $398 \mathrm{p}$.

And RetTA Stefano, PÉquignot Stéphane, Schaub Marie-Karine, Windler Christian éd., 2010, Paroles de négociateurs. L'entretien dans la pratique diplomatique de la fin du Moyen Âge à la fin du xıxe siècle, Rome, École française de Rome, 446 p.

Argumentation et analyse du discours, 2011, n6, L'analyse rhétorique aux États-Unis. Hommage à Michael Leff, en ligne [http://aad.revues.org/], consulté le 23 mai 2011.

ARQUEMBOURG Jocelyne, 2011, L'événement et les médias. Les récits médiatiques des tsunamis et les débats publics (1755-2004), Paris, Archives contemporaines, $203 \mathrm{p}$.

ATtALI Michael éd., 2010, Sports et médias. Du xixe siècle à nos jours, Biarritz, Atlantica, $840 \mathrm{p}$.

Aubert Nicole, Haroche Claudine éd., 2011, Les tyrannies de la visibilité. Être visible pour exister?, Toulouse, Érès, $360 \mathrm{p}$.

BAcot Paul, 2010, La politique en 350 quiz, réédition, Paris, Rue des Écoles (Les quiz du Monde), $96 \mathrm{p}$.

- 2011, La construction verbale du politique. Études de politologie lexicale, Paris, L'Harmattan, 2011, $174 \mathrm{p}$.

BAnNiARD Michel et PhILPS Dennis éd., 2010, La fabrique du signe. Linguistique de l'émergence, Toulouse, Presses universitaires du Mirail, $334 \mathrm{p}$.

BERT Jean-François, 2011, Introduction à Michel Foucault, Paris, La Découverte, 128 p.

BLANDIN Claire, ECK Hélène éd., 2010, La vie des femmes. La presse féminine auxxıxe et xxe siècles, Paris, Panthéon Assas, 148 p.

BLEVIns Jane, 2010, L'écrivain et son public à l'ère de la radio. D'Edgar Allan Poe à Paul Valéry, Paris, INA, $350 \mathrm{p}$.

Bonnafous Alain, Roulleau-Berger Laurence éd., 2011, Académiquement correct, Lyon, Presses universitaires de Lyon, $300 \mathrm{p}$. 
Bresson Gillet Sylvie, 2011, Communication et citoyenneté. L'équivoque du débat public. De la participation au débat éclairé, préface de J. Perriault, Paris, L'Harmat$\tan , 302 \mathrm{p}$.

Bruneteaux Patrick, Terrolle Daniel éd., 2010, L'arrière-cour de la mondialisation. Ethnographie des paupérisés, Bellecombe-en-Bauges, Croquant, $256 \mathrm{p}$.

CAndea Maria, MıR-SAmII Reza éd., 2011, La rectification à l'oral et à l'écrit, Paris, Ophrys, $246 \mathrm{p}$.

CAVEng Rémy, 2011, Un laboratoire du «salariat libéral». Les instituts de sondage, Bellecombe-en Bauges, Croquant, $264 \mathrm{p}$.

Cerf Martine, Horwitz Marc, 2011, Dictionnaire de la laïcité, Paris, Armand Colin, 352 p.

CHETCUTI Natacha, 2010, Vie de couple, sexualité, représentation de soi, Paris, Payot, 304 p.

CHomsky Noam, 2011, Sur la nature et le langage, traduit de l'américain par Valérie Aucouturier, Marseille, Agone, $214 \mathrm{p}$.

COMPIÈGNE Isabelle, 2011, La société numérique en question(s), Paris, Sciences humaines, $160 \mathrm{p}$.

Corcuff Philippe, 2011, B.a-ba philosophique de la politique pour ceux qui ne sont ni énarques, ni politiciens, ni patrons, ni journalistes, Paris, Textuel, $144 \mathrm{p}$.

Corroy Laurence, Roche Émilie, 2010, La presse en France depuis 1945, Paris, Ellipses, $144 \mathrm{p}$.

DAmbRe Marc, GolsAn Richard J., 2010, L'exception et la France contemporaine. Histoire, imaginaire, littérature, Paris, Presses de la Sorbonne nouvelle, 288 p.

Delavaud Gilles, Maréchal Denis éd., 2011, Télévision. Le moment expérimental. De l'invention à l'institution (1935-1955), Rennes, Apogée, 608 p.

DelPORTE Christian, 2011, Une histoire de la séduction politique, Paris, Flammarion, $384 \mathrm{p}$.

DenouëL Julie, Granjon Fabien éd., 2011, Communiquer à l'ère numérique. Regards croisés sur la sociologie des usages, Paris, Presses des Mines, $320 \mathrm{p}$.

Deschoumer Kris, Delwit Pascal, Hooghe Marc, Walgrave Stefaan éd., 2010, Les voix du peuple. Le comportement électoral au scrutin du 10 juin 2009, Bruxelles, Université de Bruxelles, $332 \mathrm{p}$.

DERVIN Fred, 2010, Lingua francas. La véhicularité linguistique pour vivre, travailler et étudier, Paris, L'Harmattan, $246 \mathrm{p}$.

Dufaye Lionel, Gournay Lucie éd., 2010, L'altérité dans les théories de l'énonciation, Paris, Ophrys, $195 \mathrm{p}$.

FAgYal Zsuzsanna, 2010, Accents de banlieue. Aspects prosodiques du français populaire en contact avec les langues de l'immigration, Paris, L'Harmattan, $216 \mathrm{p}$.

Gaboriau Simone, Pauliat Hélène éd., 2011, La parole, l'écrit et l'image en justice. Quelle procédure au xxıe siècle?, Limoges, PULIM, 212 p.

Gorius Aurore, Moreau Michaël, 2011, Les gourous de la com'. Trente ans de manipulations politiques et économiques, Paris, La Découverte, $311 \mathrm{p}$.

Grzmil-TyLUtKı Halina, 2010, Francuska lingwistyczna teoria dyskursu. Historia, tendencje, perspektywy, Cracovie, Université Taiwpn, 366 p.

GuILBERT Thierry, 2011, L'«évidence» du discours néolibéral. Analyse dans la presse écrite, Bellecombe-en-Bauges, Croquant, $136 \mathrm{p}$.

HaILON Fred, 2011, Idéologie par voix/e de presse, Paris, L'Harmattan, 300 p. 
Houdebine-Gravaud Anne-Marie, 2011, Trésor de la langue ordinaire. Journée en hommage à Claudine Normand, Paris, Ophrys, $112 \mathrm{p}$.

KACIAK Nicolas, LegaVRe Jean-Baptiste éd., 2011, Communication interne et changement, Paris, L'Harmattan, $258 \mathrm{p}$.

KJAER Anne-Lise, AdAMo Silvia éd., 2011, Linguistic Diversity and European Democracy, Copenhague, Ashgate, $242 \mathrm{p}$.

LAMIZET Bernard, 2011, Le langage politique. Discours, images, pratiques, Paris, Ellipses, $256 \mathrm{p}$.

Langage et société, 2011, nº135, Méthodes d'analyse des discours, J. Boutet, D. Demazière éd., $126 \mathrm{p}$.

LAVILLE Camille, 2011, Les transformations du journalisme de 1945 à 2010. Le cas des correspondants étrangers de l'AFP, Paris, INA-De Boeck, 233 p.

LEIMDORFER François, 2011, Les sociologues et le langage, Paris, MSH, 292 p.

Lidil, 2010, nº 4, Énonciation et rhétorique dans l'écrit scientifique, F. Boch, F. Rinck éd., $160 \mathrm{p}$.

LITS Marc, 2011, Le roman policier dans tous ses états, d'Arsène Lupin à Navarro, Limoges, PULIM, $194 \mathrm{p}$.

LoNGH Julien, 2011, Visées discursives et dynamiques du sens commun, Paris, L'Harmattan, $175 \mathrm{p}$.

LÜDI Georges éd., 2010, Le plurilinguisme au travail entre la philosophie de l'entreprise, les représentations des acteurs et les pratiques quotidiennes, Bâle, Institut für Französische Sprach- und Literaturwissenschaft, $179 \mathrm{p}$.

MARIN Richard, 2011, Les mots du Brésil, Toulouse, Presses universitaires du Mirail (Les Mots de), $128 \mathrm{p}$.

MAUdUIT Laurent, 2011, Les 110 propositions. 1981-2011, Paris, Seuil.

MAYER Nonna, 2010, Sociologie des comportements politiques, Paris, Armand Colin, $316 \mathrm{p}$. MeYer Vincent éd., 2010, Normes et normalisation en travail social. Pour une posture critique entre responsabilité, résistance et créativité, Bordeaux, Les Études hospitalières, $178 \mathrm{p}$.

MoRdillat Gérard, Rothé Bertrand, 2011, /l n'y a pas d'alternative, Paris, Seuil.

NiCEY Jérémie, PALMER Michael, 2011, Lexique subjectif de l'homme informant, Paris, L'Amandier, $327 \mathrm{p}$.

Normand Claudine, 2010, Petite grammaire du quotidien. Paradoxe de la langue ordinaire, Paris, Hermann, $240 \mathrm{p}$.

PALmer Michael, 2011, Homo informans. L'urgence des news au fil des millénaires, Paris, L’Amandier, $454 \mathrm{p}$.

Parlement(s), 2011, n ${ }^{15}$, Parlements et parlementaires en France au xvIIIe siècle, F. Bidouze éd.

Piet Gregory, Wintgens Sophie, StAns David, 2010, La guerre de Gaza. De l'analyse du discours médiatique à l'analyse politologique, Bruxelles, Peter Lang, $226 \mathrm{p}$.

Pifarré Alexandra-Flora, Rutigliano-DASPet Sandrine éd., 2010, Re-Répéter - Répétition, Chambéry, Université de Savoie, $272 \mathrm{p}$.

Plantin Christian, 2011, Les bonnes raisons des émotions. Principes et méthode pour l'étude du discours émotionné, Bruxelles, Peter Lang, 306 p. 
Pugnière-SAAVEd Ra Frédéric, 2011, Le phénomène Deschiens à la télévision. De la genèse d'un programme sériel à la manifestation de l'humour, Paris, L'Harmattan, $284 \mathrm{p}$.

QuIDOT Sylvain, 2011, La conversation banale. Représentations d'une sociabilité quotidienne, Paris, L'Harmattan, $220 \mathrm{p}$.

RAMONET Ignacio, 2011, L'explosion du journalisme. Des médias de masse à la masse de médias, Paris, Galilée, $160 \mathrm{p}$.

RECK Isabelle, 2011, Nuevo teatro español (1965-1978). De l'enchantement textuel au désenchantement, Strasbourg, Presses universitaires de Strasbourg, $234 \mathrm{p}$.

Rowel Jay, SAInT-GILle Anne-Marie éd., 2010, La société civile organisée aux XIxe et $x x$ siècles. Perspectives allemandes et françaises, Villeneuve d'Ascq, Presses universitaires du Septentrion, $374 \mathrm{p}$.

Semen, 2010, $\mathrm{n}^{\circ}$ 30, Les langages de l'idéologie. Études pluridisciplinaires, C. Lambert, P. Schepens éd., $204 \mathrm{p}$.

Semen, 2011, n³1, Polémiques médiatiques et journalistiques. Le discours polémique en question, R. Amossy, M. Burger éd., 206 p.

SOUlEz Guillaume, 2011, Quand le film nous parle. Rhétorique, cinéma, télévision, Paris, PUF, $256 \mathrm{p}$.

TOURNÈs Ludovic éd., 2010, L'argent de l'influence. Les fondations américaines et leurs réseaux européens, Paris, Autrement, 208 p.

TRAT Josette éd., 2011, Les cahiers du féminisme (1977-1998). Dans le tourbillon du féminisme et de la lutte de classes, Paris, Syllepse, $352 \mathrm{p}$.

Vargas Claude, Calvet Louis-Jean, Gasquet-Cyrus Médéric, Véronique Daniel, Vion Robert éd., 2010, Langues et sociétés. Approches sociolinguistiques et didactiques, Paris, L'Harmattan, $298 \mathrm{p}$.

VEGA YVEGA Jorge Juan, 2011, Qu'est-ce que le verbe être ?Éléments de morphologie, de syntaxe et de sémantique, Paris, Champion, $280 \mathrm{p}$.

Josette Lefèvre

Université de Picardie Jules Verne, CNRS (CURAPP)

josette.lefevre@u-picardie.fr 